\title{
Development of a Web-Based Learning System to Engage Students in Question Generation Activities
}

\author{
Chun-Ping Wu and Shu-Ling Wu
}

\begin{abstract}
The strategy of student generated question engages students in deeply interacting with the newly learned contents, examining their learning outcomes, and practicing asking questions and generating answers. Grounded on the potential of this strategy, this study aims to develop a web-based system to engage students in question generation activities. A single group pre-and-posttest experimental design was adopted to further explore its effects on students' learning gains. Sixty one college students participated in the study for four weeks. The findings show that students learning is significantly enhanced by the SGQ strategy. Furthermore, students' perquisite knowledge is significantly correlated with the quality of the questions students generated. Last, students who generated questions of better quality are found to perform better in the post-knowledge assessment. Suggestions for instructional practice and future studies are provided. .
\end{abstract}

Index Terms-Student generated question strategy, a web-based learning system, learning gain

\section{INTRODUCTION}

Asking a good question is critical in the learning process. Students, who well use their knowledge to observe and interpret the newly learned contents, usually ask a good question worthy of further exploration. Therefore, in addition to encouraging students to ask questions, educators need to facilitate students in connecting their existing knowledge with new knowledge, which may enhance students' ability to ask a good question.

The strategy of Student-generated question (SGQ) assigns the evaluation task to the students, which students play the role of a teacher and create an assessment tool to evaluate students' mastery of the newly learned content. During the process, students need to identify important concepts as the core of their questions, design the question items, provide a better/correct answer, and constantly revise their questions. Such a process does not only engage students in searching for questions and answers, but also provide an opportunity for students to deliberately practicing asking a good question. The positive effects of the strategy on students' self-reported motivation and cognitive strategies use were evidenced in prior studies [1]-[4]. More research studies in exploring its effects on students' knowledge gains using objective measures are needed.

Manuscript received December 2, 2016; revised April 3, 2017.

Chun-Ping $\mathrm{Wu}$ is with the Department of Educational Technology, TamKang University, New Taipei City, Taiwan (e-mail: cp_learning@gms.tku.edu.tw).

Shu-Ling $\mathrm{Wu}$ is with the Department of Educational Psychology and Counseling, National Tsing Hua University, Hsinchu City, Taiwan (e-mail: sulin@g2.nhcue.edu.tw).
This study aims to develop a web-based question generation system, which allows students to compose and revise questions, observe their peers' questions and receive instant feedback from their peers. Furthermore, a user experience testing was conducted to ensure the quality of the system. Last, but most importantly, an empirical experiment was conducted to explore the effects of the SGQ strategy.

\section{LITERATURE REVIEW}

The literature regarding the SGQ strategy and cognitive load theory will be review and discussed.

\section{A. SGQ Strategy}

The SGQ strategy is defined as students using their newly learned knowledge to compose a series of questions to assess their peers. First, students need to create the core of the question, by recalling what have learned and identifying important concepts and concepts which their peers might be confused about. Second, they need to construct the question stems by deeply examining the meaning the concepts, and the relationships among different concepts. Then they translate their understanding into the question wording. Third, when designing the answers, they experience a micro problem-solving process [5]. Specifically, they need to offer several possible solutions to the question they raise, carefully examining and testing the solutions to ensure the best/correct answer is obtained. The above process facilitates students in recalling, analyzing, organizing and synthesizing the learning content [6], evaluating self-understanding of the concepts[7], elaborating understanding of the learned content into the content of questions, which helps to schema construction [8] [9]. The positive impacts of the SGQ strategy on learning motivation, higher order thinking, cognitive and metacognitive strategies use were empirically validated in prior studies [1]-[4].

\section{B. The Cognitive Load Theory and SGQ System Development}

Students without prior experience in question, generation, usually feel the activity novelty, challenging but difficult [10]. According to the cognitive load theory, students have to devote cognitive efforts to the question generation tasks. For those students without experience in question generation or pre-requisite knowledge regarding the newly learned contents, the question generation tasks will impose them a lot of intrinsic cognitive load [11]-[13]. At the same time, the explanation of the task requirements and the way students are asked to present their products (i.e. questions) will also impose their extraneous cognitive loads. If the intrinsic and extraneous cognitive load exceed students' limited cognitive 
capacity [14], the potential learning effects brought by the SGQ strategy will not occur. Therefore, it is essential to develop an online SGQ environment, which does not only reduce any possible extraneous cognitive load, but also allow students to create and revise question easily and enhance the quality of their questions via peer feedback activities.

To sum up, the SGQ strategy engages students in deeply interacting with the learned contents. Therefore it is reasonably to propose the following hypotheses:

Hypothesis 1: Students' pre-requisite knowledge regarding the newly learned content will be correlated with the quality of the questions students generate.

Hypothesis2: Students' mastery of the newly learned content will be enhanced by being engaged in the SGQ activity.

Hypothesis3: Students' mastery of the newly learned content will be correlated with the quality of the questions students generate.

\section{RESEARCH METHOD}

This study consists two stages: First, the web-based SGQ system was designed and developed by the research team. Ten college students with experience in question-generation were invited as the participants for the user experience (UX) testing. Second, the single group pretest-and-posttest experimental design was adopted. Sixty-one students, include 47 undergraduate and 14 graduate students were recruited to participate in the four-week experiment. The contents chosen are one test-construction theory and three educational psychology theories while the multiple choice question is selected as the type of question students have to compose.

\section{A. Variables and Instruments}

User experience (UX) is defined as question-authors' behavior and feeling, which is adopted to evaluate usability and ease of use the web-based SGQ system. The 10 invited question-authors were asked to conduct a series of question-generation tasks within the system. The users' action, operation path and time to conduct each sub-task were recorded by the Morae to evaluate whether the system accommodate users' intuitive operation. After that, each question-author is asked to rate the quality of "the question-posing function", "the question-management function", "navigation and interface" and "the visual appeal". The system was revised based on the user experience testing results before conducting the second stage of the study.

The quality of the questions students generate were evaluated by six dimensions: fluency, flexibility, elaboration, originality, cognitive level and importance [15]. Fluency (0 6) refers to the correctness of the wording and clarity of the meaning. Flexibility (0 2) refers to consisting several concepts and self-derived examples. Elaboration (0 2) refers to creating scenarios for the questions. Originality (0 2) refers to using creative way to design or present the question. Cognitive level (0 4) refers to the cognitive demanded for composing this question. Importance (0 2) evaluates whether the question assess important concepts. Two raters were recruited to rate each question using the six indicators.
The scores received from the raters were averaged per question per week throughout the activity.

The pre-requisite knowledge was assessed by 24 multiple choice questions, which evaluated participants' knowledge about the previously mentioned four theories before being engaged in the SGQ activity. The difficulty of the items range from 0.3 to 0.7 .

Students' mastery of the four theories after the experiment was assessed by another 24 multiple choice questions.

\section{B. Experiment Procedures}

Sixty-one students participated in the four-week workshop. At the beginning of the study, the pre-requisite assessment was administered. The training on the question generation task and the web SGQ system were introduced. Participants were asked to practice composing one question within the system. The workshop instructor selected four questions and facilitated participants in discussing how to improve the selected questions. During the experiments, per weekly, the workshop instructor delivered 2.5 hour lecture on one theory and the participants were asked to compose four questions after the lecture within 30 minutes.

\section{RESUlTS}

\section{A. The Web-Based SGQ System}

This study developed the web-based SGQ system which was named as Knowledge Management and Question Authoring System. The system was revised based on the user experience testing results. Two subsystems (question-generation and peer-assessment) were embedded in the system.

The question-generation sub-system includes three functions:

1) Question-posing function

As shown in Fig. 1, the left side of the interface allows users to type in question stems and four options, set up correct answers, and select cognitive levels and concepts. To facilitate users in recalling the concepts, the system allows the instructor to present the concepts in the format of "concept-map". Then the user could click the button of "concept-map" and read the groups of concepts (see Fig. 2). S/he may select the concepts to be the core of the question by simply clicking the concepts in the concept-map. The concepts being selected will be automatically inserted into the question-posing interface.

The right side of the interface allows users to preview the questions they construct before submitting to the system.

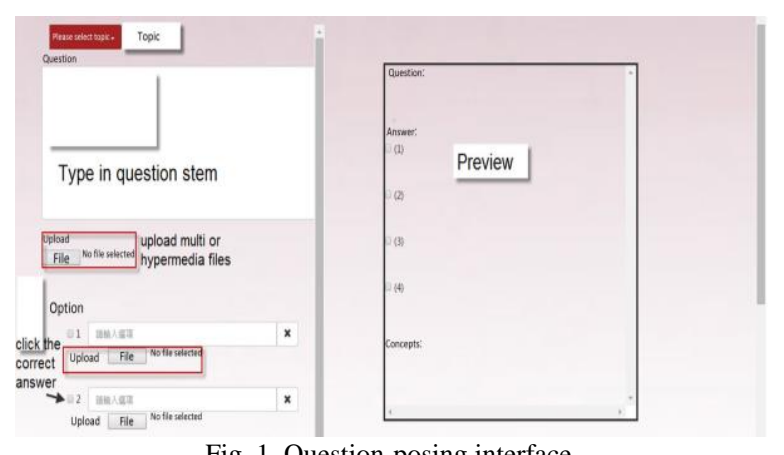

Fig. 1. Question-posing interface. 


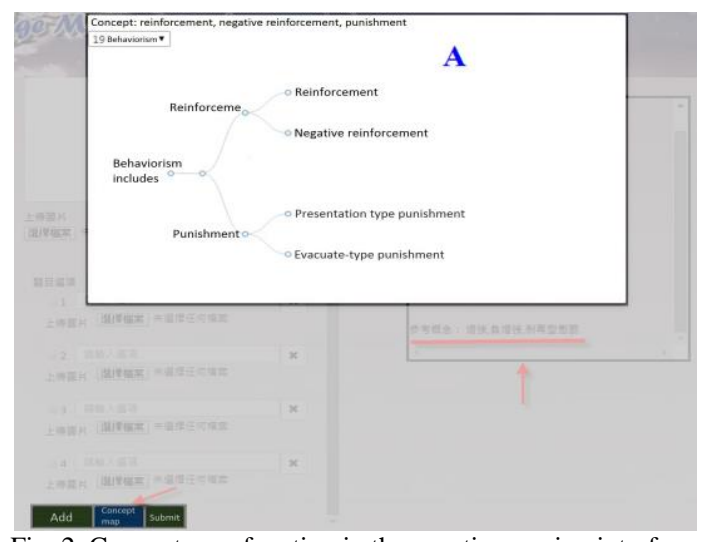

Fig. 2. Concept map function in the question-posing interface.

2) Question management function

The question management function (see Fig. 3) allows users to manage the questions and edit the questions. Additionally, users could export the questions into the pdf format.

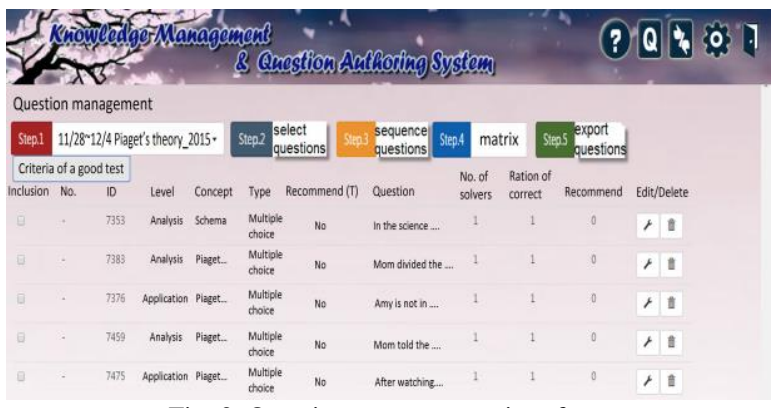

Fig. 3. Question-management interface.

3) Feedback-review function

The feedback review function allows users to read the feedback given by the instructor or the peers. When users click the button "a" (see Fig. 4), the feedback given by the peers will appear in the area of " $b$ ". The question author could read the feedback and respond to the feedback as well.

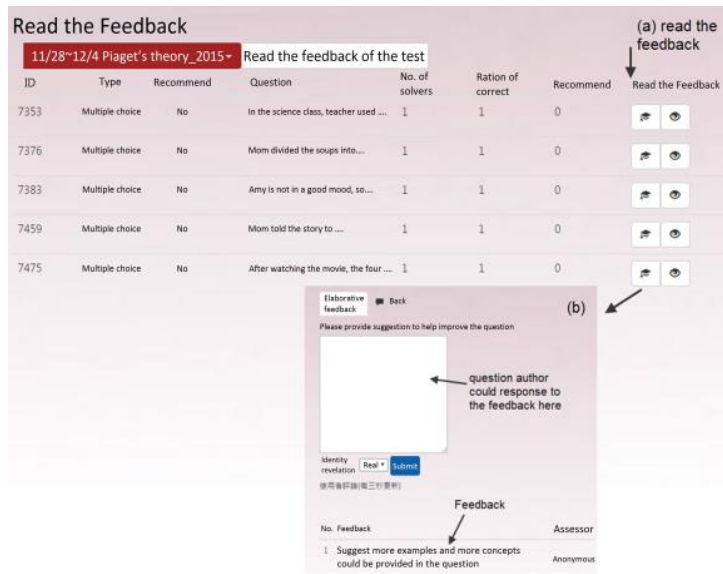

Fig. 4. Feedback review interface.

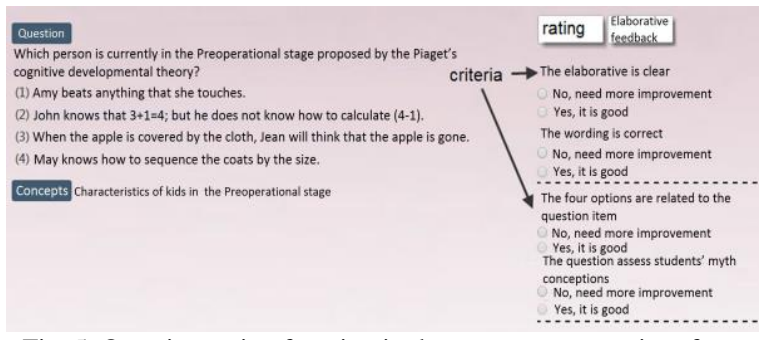

Fig. 5. Question-rating function in the peer-assessment interface.
The peer-assessment sub-system, although not being used in the second stage of this study, was created for the users to observe and review the questions composed by their peers. They learn to rate the peers' questions according to the given criteria (see Fig. 5) and then provide elaborative suggestions to help their peers to improve the questions (see Fig. 6).

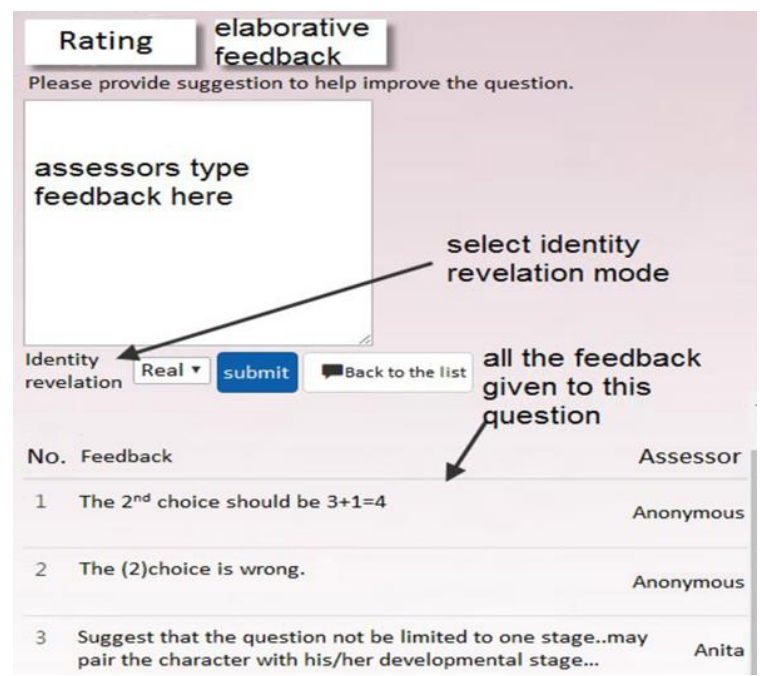

Fig. 6. Elaborative feedback function in the peer-assessment interface.

B. The Students' Pre-requisite Knowledge Is Correlated with the Quality of the Questions Students Generate

The students' scores gained in the four pre-requisite knowledge tests are presented in Table I. Moreover, as shown in Table II, the quality of students' questions ranges from 12.73 to 15.25 .

TABLE I: THE PRE-REQUISITE KNOWLEDGE

\begin{tabular}{llllll}
\hline \hline Topic & Topic 1 & Topic 2 & Topic 3 & Topic 4 & Sum \\
\hline Mean & 10.49 & 31.15 & 13.44 & 9.05 & 64.13 \\
SD & 3.59 & 6.41 & 4.32 & 5.51 & 14.29 \\
Perfect & 16 & 40 & 20 & 20 & 96 \\
score & & & & & \\
\hline \hline
\end{tabular}

TABLE II: THE QUALITY OF STUDENTS' QUESTIONS

\begin{tabular}{lcccc}
\hline \hline Topic & Topic 1 & Topic 2 & Topic 3 & Topic 4 \\
\hline Mean & 12.73 & 15.25 & 13.03 & 14.33 \\
SD & 3.93 & 2.40 & 3.03 & 1.70 \\
Perfect & 18 & 18 & 18 & 18 \\
score & & & & \\
\hline \hline
\end{tabular}

TABLE III: THE POST-TEST SCORES

\begin{tabular}{llllll}
\hline \hline Topic & Topic 1 & Topic 2 & Topic 3 & Topic 4 & Sum \\
\hline Mean & 10.42 & 35.48 & 14.95 & 11.67 & 72.53 \\
SD & 3.81 & 5.73 & 3.57 & 5.90 & 12.45 \\
$\begin{array}{l}\text { Perfect } \\
\text { score }\end{array}$ & 16 & 40 & 20 & 20 & 96 \\
$\begin{array}{l}\text { T (post vs. } \\
\text { pretest) }\end{array}$ & -0.12 & 4.74 & 2.4 & 4.68 & 5.94 \\
P-value & .90 & .00 & .02 & .00 & .00 \\
\hline \hline
\end{tabular}

The correlation result show that the students' pre-requisite knowledge is significantly correlated with the quality of the questions students generated $(r=.23, p<0.01)$. In other words, students with better pre-requisite knowledge tended to generate questions of better quality.

\section{Students' Mastery of the Newly Learned Content Is} Enhanced by Being Engaged in the SGQ Activity 
The students' scores gained in the four post-tests are presented in Table III. The pair-t test result show that students' mastery of the newly learned contents is significantly higher than the knowledge at the beginning of the study $(t=5.94, p<0.01)$. In other words, students' mastery of the theories is enhanced by being engaged in the SGQ activities.

\section{Students' Mastery of the Newly Learned Content Is Correlated with the Quality of the Questions Students Generated}

The correlation result show that the students' performance in the post tests is significantly correlated with the quality of the questions students generated $(r=.25, p<0.01)$. In other words, students who generated questions of better quality tended to gain higher scores in the post-tests.

\section{CONCLUSION}

A web-based SGQ system was developed in this study to engage students in the activity of composing questions. The empirical findings substantiated the educational benefits of the SGQ strategy on enhancing students' learning outcomes. Additionally, the finding contributed to understanding that students' pre-requisite knowledge may affect students' engagement in the SGQ activity. Instructors are suggested to adopt this creative strategy rather than traditional drill-and-practice activities to enhance students' interaction with the knowledge. Those students without well pre-requisite knowledge may need more attention from the instructor. To avoid students being overloaded by the SGQ and peer-assessment activities, this study did not adopt peer-assessment. As found in the finding, students learning was enhanced, which could be reasonably infer that the cognitive efforts demanded by the SGQ did not exceed students' cognitive capacity. Therefore, future studies are recommended to further explore the coupling effects of these two strategies.

\section{ACKNOWLEDGMENT}

This paper was funded by research grant from the National Science Council, Taiwan, ROC (MOST 103-2511 -S-032-007-)

\section{REFERENCES}

[1] S. Abramovich and E. K. Cho, "Technology as a medium for elementary preteachers' problem-posing experience in Mathematics," Journal of Computers in Mathematics and Science Teaching, vol. 25, pp. 309-323, 2006.

[2] A. Barlow and J. M. Cates, "The impact of problem posing on elementary teachers' beliefs about mathematics and mathematics teaching," School Science and Mathematics, vol. 106, pp. 64-73, 2006.

[3] D. J. Whiten, "Exploring the strategy of problem posing," in Professional Development Guidebook for Perspectives on the
Teaching of Mathematics: Companion to the Sixty-Sixth Yearbook, G. W. Bright and R. N. Rubenstein Eds., Reston, VA: National Council of Teachers of Mathematics, 2004, pp. 1-4.

[4] F. Y. Yu, "Promoting metacognitive strategy development through online question-generation instructional approach," in Proc. International Conference on Computers in Education, Singapore: Nanyang Technological University, 2005, pp. 564-571.

[5] F.-Y. Yu, Y.-H. Liu, and T.-W. Chan, "A networked question-posing and peer assessment learning system: A cognitive enhancing tool," Journal of Educational Technology Systems, vol. 32, no 2 \& 3, pp. 211-226, 2005.

[6] F. I. M. Craik, "Levels of processing: Past, present, and future?" Memory, vol. 10, pp. 305-318, 2002.

[7] A. Y. Lee and L. Hutchison, "Improving learning from examples through reflection," Journal of Experimental Psychology: Applied, vol. 4, pp. 187-210, 1998.

[8] R. L. Bangert-Drowns, M. M. Hurley, and B. Wilkinson, "The effects of school-based writing-to-learn interventions on academic achievement: A meta-analysis," Review of Educational Research, vol. 74, pp. 29-58, 2004.

[9] D. M. B. Herbert and J. S. Burt, "What do students remember? Episodic memory and the development of schematization," Applied Cognitive Psychology, vol. 18, pp. 77-88, 2004.

[10] F. Y. Yu, "Scaffolding student-generated questions: Design and development of a customizable online learning system," Computers in Human Behavior, vol. 25, no. 5, pp.1129-1138, 2009.

[11] J. Sweller, "Cognitive load during problem solving: Effects on learning," Cognitive Science, vol. 12, no. 2, pp. 257-285, 1998.

[12] J. Sweller, "Element interactivity and intrinsic, extraneous and germane cognitive load," Educational Psychology Review, vol. 22, no. 2, pp. 123-138, 2010.

[13] J. Sweller, J. J. G. Merriënboer, and F. G. Paas, "Cognitive architecture and instructional design," Educational Psychology Review, vol. 10, no. 3, pp. 251-296, 1998.

[14] A. Baddeley, "Working memory," Science, vol. 255, pp. 556-559, 1992.

[15] F.-Y. Yu and C.-P. Wu, "Predictive effects of online peer feedback types on performance quality," Educational Technology \& Society, vol. 16, no. 1, pp. 332-341, 2013.

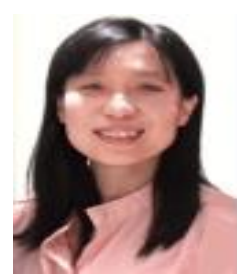

Chun-Ping Wu is from Taipei, Taiwan. She earned her $\mathrm{PhD}$ in the profession of instructional design, development and evaluation from Syracuse University at USA.

She is currently associate professor in the Department of Educational Technology at Tamkang University at Taiwan. She is interested in designing innovative technology to enhance students' learning motivation and problem-solving skills. Her research focuses on developing learning systems and board game centering on students generated questions strategy and cognitive strategy use. Her research papers have been published in Computers \& Education (SSCI), Journal of Education Technology (SSCI), Journal of Research in Education Sciences (TSSCI) and others.

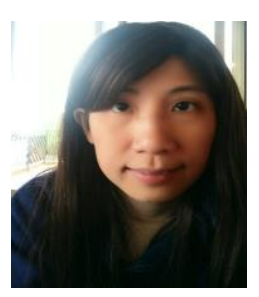

Shu-Ling Wu is from Taipei, Taiwan. She earned her $\mathrm{PhD}$ in the Institute of human resource management from National Sun Yat-sen University at Taiwan.

She is currently assistant professor in the Department of Educational Psychology and Counseling, National Tsing Hua University at Taiwan. Her main research areas include strategic human resource management and organization theory and positive behavior. Her research papers have been published in Total Quality management \& Business Excellence (SSCI), Journal of Technology Management (TSSCI) and others. 